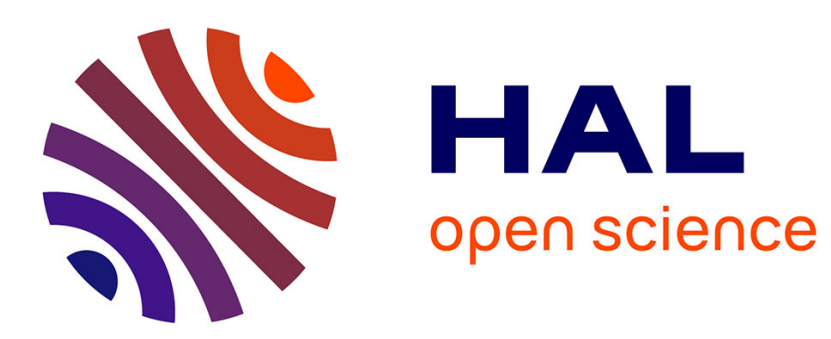

\title{
Monitoring approaches in general anesthesia: a survey.
} Lotfi Senhadji, Eric Wodey, Claude Ecoffey

\section{To cite this version:}

Lotfi Senhadji, Eric Wodey, Claude Ecoffey. Monitoring approaches in general anesthesia: a survey.. Critical Reviews in Biomedical Engineering, 2002, 30 (1-3), pp.85-97. 10.1615/CritRevBiomedEng.v30.i123.50 . inserm-00131053

\section{HAL Id: inserm-00131053 https://www.hal.inserm.fr/inserm-00131053}

Submitted on 30 Oct 2007

HAL is a multi-disciplinary open access archive for the deposit and dissemination of scientific research documents, whether they are published or not. The documents may come from teaching and research institutions in France or abroad, or from public or private research centers.
L'archive ouverte pluridisciplinaire HAL, est destinée au dépôt et à la diffusion de documents scientifiques de niveau recherche, publiés ou non, émanant des établissements d'enseignement et de recherche français ou étrangers, des laboratoires publics ou privés. 


\title{
HAL author manuscript
}

\section{Monitoring approaches in general anesthesia: A survey}

\author{
Lotfi Senhadji $^{1}$, Eric Wodey ${ }^{2}$, Claude Ecoffey ${ }^{2}$ \\ ${ }^{1}$ INSERM - Laboratoire Traitement du Signal et de l'Image \\ ${ }^{2}$ Service Anesthésie-Réanimation 2, CHU-Rennes \\ Université de Rennes1, Cedex 35042 Rennes France.
}

\section{Lotfi.senhadji@univ-rennes1.fr}

\section{Introduction}

Anesthesia allows practicing surgical or diagnostic acts if their profits for the patient are superior to anesthesia inherent risks. Anesthesia is based on combinations of pharmacological drugs administrated to the patient to induce sleep (hypnosis), avoid pain (analgesia) and to inhibit reflex or automatic muscular tonuses. The anesthetic agents alter the normal functioning of one or several nervous systems: the peripheral, the central and the autonomic nervous system. The regulation mechanisms, driven by the autonomic nervous system, can then be interrupted leading to important systemic functions disturbances, which can be amplified by the intervention (as the bleeding and the hypovolemia, ...), by the status of the patient and by the overdosing in the administered products.

One of the main tasks of the anesthetist is to maintain an adequate state of anesthesia by balancing the effects of the hypnotic, the analgesic and the muscular relaxants. If objective evaluations of the muscle relaxation is simple (measure of muscle contraction induced by an 
electrical stimulation), the "depth" of anesthesia, in terms of hypnosis and analgesia, is more difficult to define and to quantify. It depends on the used substances, their dosage and their interaction, and on the patient.

In practice, it is indirectly assessed using physiological variables (heart rate, blood pressure...) and clinical signs (perspiration, eyes position, limbs movements...), which highlight the depression of certain activities of nervous system. Although the brain is so far the main target of the administered products, the analysis of the electrical activity of the brain is rare even for general anesthesia.

\section{Anesthesia in France}

The last inquiry on the practice of the anesthesia in France goes back up to 1996 and its results were published in 1998 (1). It estimated that 8 millions of anesthesia are practiced each year. Reported to the French population, it corresponds to an annual rate of 13.5 anesthesia for 100 inhabitants. This rate varies according to the sex and to the age. From 10 years, rates increase with the age of patients. They are higher, for the women between 15 and 54 years, and for the men before 15 years and after 54 years.

A third of anesthesia is practiced on patients 60 years old and more, $55 \%$ for patients from 15 to 59 years old and $12 \%$ for children less than 15 years. In $55 \%$ of cases, the anesthesia is practiced on women. $88 \%$ of anesthesia concern patients of class ASA $1^{1}$ or 2 , where $56 \%$ are women; and the remaining $12 \%$ of anesthesia concern patients of the classes ASA3 to 5,

\footnotetext{
${ }^{1}$ ASA (American Society of Anesthesiologists) risk/complication classifications 1 Healthy Patient,

2 Patient with mild, controlled, functionally nonlimiting systemic disease,

3 Patient with severe or poorly controlled systemic disease that is functionally limiting,

4 Patient with severe systemic disease that is a constant threat to life,
} 
where $59 \%$ are men. The $90 \%$ of patients of class ASA3 to 5 are patients of more than 45 year old.

Between 1980 and 1996, the increase of the number of anesthesia is globally $120 \%$. This increase is particularly noted in three categories of population:

1) children less than 5 years where the anesthesia in ENT (Ear, Nose, Throat) represents $70 \%$ of the increase,

2) women from 20 to 39 years where obstetric anesthesia represents $63 \%$ of the increase,

3) patients more than 60 years old. Digestive endoscopy, orthopedics and ophthalmology represent $61 \%$ of the increase observed in this age range.

The general anesthesia is dominant with more than $77 \%$ of the practiced acts. For a number of anesthesia estimated to 6,7 millions, a unique anesthetic agent is administered, by intravenous injection or inhalation, with or without association of a local anesthesia. It concerns, in $59 \%$, the surgery and more particularly the orthopedic, digestive field and ENT (respectively $26 \%, 13 \%$ and $12 \%$ of the entire general anesthesia). In $72 \%$ of the single general anesthesia, 3 products at least are used and only $3 \%$ contain just one (hypnotic) drug.

The risk associated to the anesthesia within the context of the operating room risk is rather weak but remains difficult to exactly estimate (2). Deaths Attributable to the anesthesia represent 2 to $10 \%$ of the entire deaths reported in the operating roam. The INSERM inquiry of 1983 (3) establishes this risk to 1/12000 in France. It shows, based on 198103 anesthesia practiced in France from 1978 to 1982, that the risks of the most critical accidents and of death are maximum at the recovery phase (due to respiratory depression). The decree $\mathrm{n}^{\circ}$ 94- 
1050 of December 5, 1994 concerning the safety of anesthesia requires, for every scheduled anesthesia, a medical consultation with an anesthetist and the checking of a list of materials and devices. The purpose is to practice the anesthesia according to an established protocol, which includes the patient state and its inherent risks.

The risk of anesthesia is composed by predictable and unpredictable accidents. The cardiocirculatory and respiratory accidents are the predictable ones. They may be circulatory arrest often due to hypovolemia during induction, to respiratory depression in the recovery phase, to inhalation of the gastric contents (patient not on an empty stomach) particularly in emergency, and to complications related to the tracheal intubation.

Unpredictable accidents could be connected to the dysfunction of the used material (mixer of gas, manometer ...), to errors of manipulation, to the non checking of certain devices before use (notably in emergent anesthesia), to an anaphylactic shock to anesthetics or to unknown disease revealed with the anesthesia, and to a surgical discovery. Explosion or electrical breakdown are very rare accidents, malign hyperthermia is an exceptional accident.

The previous paragraphs underline the importance of the anesthesia and its utility in term of health care. The evolution over the last ten years has allowed patients at the extreme ages to benefit from the surgery.

\section{Monitoring in general anesthesia}

Anesthetics obey to the pharmacokinetic and pharmacodynamic laws and each product has its own characteristics. They are only effective starting from a minimal concentration in the nervous tissues or in the bloody plasma. As their effects decrease in the time in an exponential way, they must be administered continuously or periodically. The required dose for a given 
effect is not the same for all the patients. Each product is administered according to a specific curve, which indicates the required quantity to efficiently anaesthetize (insensitivity to incision) $50 \%$ of patients (the Minimal Alveolar Concentration - MAC for the case of halogenated gasses). Therefore the injected intravenous dose and/or the concentration of inhaled gas can be approximately adapted to a given patient (too deep or too light anesthesia)

\section{III.1 Clinical practice}

The decree $n^{\circ}$ 94-1050 of December 5, 1994 concerning the safety of anesthesia requires the monitoring of the cardiovascular and the respiratory systems. In clinical routine, the ECG signal and the heart rate are monitored as well as the blood pressure obtained invasively or not (according to the status of the patient). The amount of inspired oxygen is controlled as well as the oxygen blood saturation. Most of the general anesthesias include a tracheal intubation and artificial ventilation to avoid the risks of respiratory depression. The expired concentration of carbon dioxide and the anesthetic gas, if the later is used, are then monitored.

These parameters are relevant for the follow-up of the clinical status of the patient but are relatively poor as regard to the evaluation of the depth of anesthesia. There is no objective scale between a " too light " and a " too deep " anesthesia. The consequence of a too light anesthesia maybe at least memorization of what happened in the operating room, or at most the occurrence of a myocardial ischemia for a coronary patient. The consequence of a too deep anesthesia could be the necessity of a hemodynamic assistance with vasoconstrictor agents to maintain a normal blood pressure, a normal cardiac output and a respiratory assistance post-operatively or a secondary respiratory depression due to an overdosing in anesthetic agents. 
At present, the assessment of the depth of anesthesia is essentially based on clinical signs to evaluate a reaction to a too painful stimulus and/or to a too light anesthesia for a given surgical act: movement of the patient, if muscle relaxants were not used, essentially an increase of the heart rate and of the blood pressure. Note that most of anesthetic agents have some side effects that could interfere with hemodynamic signs. Furthermore, in certain cases, these clinical signs are not available any more (cardiac arrest in heart surgery i.e. cardiopulmonary bypass).

\section{III.2 Clinical research}

Anesthesia monitoring is subject to numerous researches and stimulates the interest of big industrial groups. The investigations go from the simple analysis of a single signal, for the production of an alarm, to the extraction and the combination of several parameters for the automatic control of a closed loop system. In addition to the previously mentioned signals, the reported methods are based upon a continuous EEG recordings or Evoked Potential (EP) by sensorial stimulation, and on EMG signals.

\section{III.2.1 EEG in anesthesia}

The absorption of anesthetic agents, in variable doses, modifies in a more or less pronounced way, frequency and mean amplitude of the EEG (4). For the most part of volatile and intravenous hypnotic drugs as the propofol, the benzodiazepines and the barbiturates, the inspection of the EEG reveals morphological changes. In low doses, the mean frequency of 
the EEG increases (activation) mainly the $\beta$ band $(>13 \mathrm{~Hz})$ and its mean power decreases in the $\alpha$ band $(8-13 \mathrm{~Hz})$. By increasing the dose, the mean frequency of the signal decrease and its amplitude increases and $\theta(4-7 \mathrm{~Hz})$ or $\delta(<4 \mathrm{~Hz})$ waves appear. For high doses of certain agents, the EEG exhibits a particular pattern called Burst-Suppression, which is a succession of periods of silence or isoelectric (amplitude $<5 \mu \mathrm{V}$ ) and of discharge, and finally becomes flat (5). The effect of certain classes of anesthetic agents on the EEG moves away from this description. For example, the opioids slow down the EEG without the initial phase of activation whereas benzodiazepines do not lead to burst-suppression phenomenon. Generally, two different agents produce different morphological modifications on the EEG and their effects are not cumulative. Furthermore, these morphological figures are not specific to the anesthesia. Indeed, a severe cortical deterioration can induce similar EEG modifications as those observed under the influence of an anesthetic (6) (7). Therefore the inspection of the EEG signal for interpretation and diagnostic, during an anesthesia, is not easy and requires a meticulous learning.

The main goal of processing EEG signals is to derive, reliable and reproducible, quantitative parameters which correlate with the clinical status of the patient (physiological and pharmacological).

Artifacts, which often corrupt the EEG, are from different origins. They could be related to biological sources (i.e. the electromyogram and/or the electrocardiogram, the eye movements), to the acquisition devices (i.e. saturation of amplifiers induced by movements of electrodes, power line interference), or furthermore to the particular conditions of recording (electro-surgical instruments, diathermy knife, pump, ...). To reduce these artifacts, temporal (as filtering) or spectral methods (estimation of the spectral contents by FFT or AR modeling) but also approaches based on heuristic considerations (correlation among sensors, locations 
on privileged channels, duration of activities, ...) are used. Nevertheless, the portions of signal moderately or strongly corrupted, where characteristic events may be present, are excluded from the analysis.

On the other portions of EEG, different signal processing techniques were used. Temporal methods derive parameters related directly to the amplitude or to the distribution of the EEG. Mean power on a sliding window was one of the first monitors extracted from the EEG and correlated to the administered anesthetic dose (8). Works conducted in $(9,10)$ evidenced a relation between the frequency of zero crossings of the EEG and the concentrations of anesthetic agents but no significant correlation were established with the awakening. The zero-crossing frequency of the EEG is also correlated with the ability of a patient to execute a simple command (11). However, the authors conclude that this parameter presents a high variability, which limits its use. The measure of the relative duration of EEG suppression with regard to the observation duration (i.e. Burst-Suppression Ratio) was proposed in (5) to monitor the therapeutic coma using barbiturates. This parameter was also used to automatically control a closed loop of anesthetic agent injection (12).

Frequency domain methods were also explored. The basic ingredient is the spectrum of the EEG signal obtained by the Fast Fourier Transform (in a sliding window or not) or by a parametric method (AR or ARMA). The use of the power spectral density was suggested in $(8,13)$. However, each anesthetic agent has its own characteristic effects on the EEG spectrum as pointed out in (14-17). To overcome this limitation, the works based on spectral analysis were conducted on variables or descriptors derived from the entire spectrum. The classically used parameters include: 1) dominant power frequency (DF). 2) Median power frequency (MF). 3) 90 and 95 \% spectral edge frequency (SEF) -frequency below which 90 or 
$95 \%$ of the total power of the signal is concentrated (18). 4) Power (relative to the total power or not) in particular frequency bands of the EEG.

On animal, SEF variation follows the change of the concentration of halothane and enflurane (18). These spectral characteristics exhibit important changes at the transition from the state of unconsciousness to recovery (19-21). Unfortunately, such parameters may vary significantly, in an incoherent manner, during anesthesia $(22,23)$ and do not allow predicting the patient movements in reaction to incision $(24,25)$. EEG power distribution over particular frequency bands ( $\beta, \alpha, \theta$ and $\delta$ ) has also been considered to characterize the effects of anesthesia on EEG signal (21, 26-29). It comes out that, once again, different anesthetics can produce totally different energy distributions. Spectral parameters and powers in the various frequency bands of the EEG were simultaneously used in particular works (30-32). The combination of these descriptors, based on linear and nonlinear procedures, seems to be correlated with anesthetic agent dosages. The linear approaches are highly variable and nonlinear ones require a larger validation.

This class of methods relies on the first order statistics of the EEG signal. The use of methods based on higher order spectral analysis, more particularly the bispectrum analysis, on the EEG for the study of the states of awareness on rats, was considered in (33). A company (Aspect Medical System) proposed a monitor of the hypnotic effect of the anesthetic agents noted BIS. It is a combination of variables issued from temporal, spectral and bispectral domains. The temporal variable is related to the phenomenon of suppression of brain activity. The spectral one is derived from the spectral representation by means of the logarithm of the ratio of powers in two frequency bands (30-47 and 11-20 Hz). The last variable is the logarithm of the ratio of cumulated values of the bispectrum over two squares $(0.5,0.5-47,47$ and 40,40 - 47- 
$47 \mathrm{~Hz}$ ). Each of these variables is averaged on epochs of one-minute duration (34). This new monitor of depth of anesthesia has been the subject of many evaluation studies (35-39). For patient movements prediction after incision, the BIS provides better results compared with spectral parameters. However the prediction of absence of movement is less accurate and the interpretation of its values is dependent on the technique and the anesthetic agents used. For patients correctly analgezed (40), or anaesthetized only with the sevoflurane (41), neither the BIS nor the spectral parameters allow predicting reactions to incision. Other works showed that the BIS allows predicting the loss of consciousness and that it is correlated to the patient ability to execute simple commands (42) and that its use for the administration of certain anesthetic products allows reducing the recovery period duration in the ambulatory anesthesia (43). A recent study showed that hypnosis could be reached using the nitrous oxide without changes in the BIS monitor (44). The use of neural networks and integrator with fuzzy logic membership rules, based on EEG bispectrum analysis (not the BIS), hemodynamical parameters and the MAC, allows estimating the depth of anesthesia and the prediction of movements on animal (45).

\section{III.2.2 Evoked potential in anesthesia}

The EEG is modified when a sensory stimulation occurs. With adequate techniques, it is possible to collect these modifications called evoked potential. It is a succession of waves for which the latency of appearance measures the required time for a sensory stimulation to be collected by a receiver, and transmitted to the brain. The amplitude of the response depends on the number of neurons activated by the stimulation. The first activated generators at the cerebral cortex level are in the brain area, which is specific to the used sensory modality (occipital region for the vision, temporal for the hearing and parietal for the touch). Other 
regions of the brain are activated later, depending on the type of processing that stimulation undergoes. Evoked potentials are generally classified according to the nature of stimuli. One distinguishes so Visual Evoked Potentials (VEP) : they are obtained following a flash stimuli. Somatosensory Evoked Potentials (SEP) are provoked by means of a small electric shock applied to a peripheral nerve. Auditory Evoked Potentials: they are induced by means of emitted brief sounds (e.g.: clicks) stimulating the cochlea of the internal ear.

Two components can be distinguished in evoked potentials. The exogenous components correspond to the common part of the processing which any stimulation has to undergo. These components are usually measured in the laboratories of neurological functional investigation. They include waves, generated in the brainstem (Brainstem Evoked Potential) and appearing in the $10 \mathrm{~ms}$ following the stimulation, and waves arising between 10 and $100 \mathrm{~ms}$ (Middle Latency Evoked Potential). The endogenous components depend on the attitude of the patient regarding the stimulation and particularly his attention. They appear especially after a time delay of $100 \mathrm{~ms}$ following the stimulation.

Studies of the anesthesia effects on evoked potential concern mainly exogenous components of Auditory Evoked Potentials (AEP) (46). The intravenous agents such as the secobarbital, the althesin, the etomidate and propofol produce changes related to the absorbed dose: the latency of the MLAEP increases and its amplitude decreases while the BAEP remains approximately unchanged (47-49). Effects of opioid agents are particular: the latency of the MLAEP is increased but this modification does not seem to be correlated to the administered dose, and the amplitude is not affected (50), which seems coherent with the fact that opioid mainly possesses analgesic properties (51). The volatile anesthetic agents, such as halothane, enflurane and isoflurane, also produce concentration dependant changes on the latency of 
BAEP and MLAEP, and the amplitude of this later decreases (52-55). Other studies showed that the MLAEP can predict movement during the tracheal intubation (56) and recovery (57, 58) and a monitor based on the MLEAP, noted AEP index, has been proposed (59). Comparative studies conducted between the BIS index, the AEP index and the spectral parameters $(56,60,61)$ show that the AEP allows better distinguishing the transition from unconsciousness to consciousness and predicting patient movement during intubation. Recent works try to exploit the MLAEP to estimate and to control the depth of anesthesia. A subset of a wavelets decomposition of the MLAEP is used as the input of a neural network which estimates depth of anesthesia and, by means of decision rules based on fuzzy logic, control the propofol dosing (62).

\section{III.2.3 ECG in anesthesia}

In contrast with the EEG, the ECG signal is routinely monitored in general anesthesia. The heart rate variability is caused by the fluctuation in sympatic and parasympatic tones and reflects the influence of autonomic nervous system on the functioning of the cardiac muscle. Briefly, sympatic stimulation increases the heart frequency (chronotropic effect) and myocardial contractility (inotropic effect), causes a vasoconstriction of the peripheral vessels, increases the afterload, increases the myocardial excitability (bathmothropic effect) and decreases the delays of conduction (dromotropic effect). Parasympathic stimulation is having approximately inverse effects. Sympatic tone stimulates simultaneously atrias and ventricles and parasympatic acts mainly on atrias.

Spectral analysis allows evaluating the variability of heart rate and provides an estimation of the influence of each tone $(63,64)$. The high frequency (HF) components correspond to the 
parasympatic activity modulated by breathing (respiratory arrhythmia). Low and very low frequencies (LF and VLF) are influenced by both tones. The general anesthesia depresses the variability of heart rate (65-69) and inhibits its adaptability to blood pressure changes (70). Works conducted in (71) showed that the amplitude of the respiratory arrhythmia decreases in presence of isoflurane and nitrous oxygen and that the spectral components of heart rate increase in the recovery phase. The effect of volatile agents in heart rate was also considered in (66): total power and powers in HF, LF and VLF bands decrease during the anesthesia and the depression in the LF band is more pronounced without any significant difference between the halothane and the isoflurane. The effects of the propofol in heart rate are reported in (72) : variability in high frequencies is more depressed than in low frequencies and the shape of heart rate spectrum evolves with the depth of anesthesia. Such significant variations on the spectral components of heart rate were also described in (69) during a general anesthesia associating several volatile and intravenous anesthetic agents. Other works showed that, under general anesthesia by enflurane or isoflurane, heart rate variability is correlated to the occurrence of EEG burst-suppression patterns $(73,74)$. Heart rate increases during the burst and decreases at the onset of the suppression. However, this correlation is lost in the presence of atropine (75). A recent comparative study between the BIS index, the spectral parameters of the EEG and parameters derived from the heart rate (variances on epochs of 10 and 20 seconds) concluded that the BIS index offers a better differentiation between unconscious and conscious patients (76).

\section{III.2.4 Other biomedical signals in anesthesia}

The frontal electromyogram allows reflecting the psychological stress of the patient (9). Studies showed that the amplitude of this signal is correlated to the movements of the patient 
and to the transitions from the unconsciousness to the consciousness state and conversely, without however any possibility to predict the occurrence of transitions $(77,78)$. Comparison led in (78) between the EMG, the BIS index and the spectral parameters concludes that BIS is the best monitor of the occurrence of transitions. Unfortunately, results are not stable (big variability among individuals). The spontaneous contractility of the esophagus is modulated by autonomic nervous system. It was also proposed as an indicator of the depth of anesthesia. Contractility reduces when the dose of halothane, isoflurane or propofole increases $(79,80)$. However, these results were not confirmed and the technique is sensitive to the sensor location and to the administration of vagotonics or of vagolytics.

\section{III.3 Discussion}

This review concerning the monitoring of anesthesia brings to several observations. 1) There is an important volume of publications dedicated to the subject. 2) The main motivation is the search for a global monitor capable to summarize all the information (the BIS index is the best example). 3) There is a lack of actual conclusions that may lead to efficient measures and real means of decision and/or control. 4) The exploitation of the advanced data processing methods is recent.

Most of these works are of experimental and clinical nature and concern variations of use and associations of anesthetics or analgesics drugs. The multiplicity of agents and clinical protocols widens then the combinatorial of situations. Usually, the extracted parameters from the various signals are very global (dominant frequency, average frequency in EEG,...). They might be insufficient to express short-time spectral reorganizations or complex temporal 
relations. Only few methodological works were dedicated to the anesthesia monitoring which underlines the difficulty of such a problem.

More fundamentally, this review points out the limits of approaches only based on isolated observations and so without strong links with the underlying physiological and neurophysiological processes. Deep modeling of important systemic functions and regulating mechanisms involved in the anesthesia (as the cardiovascular, the autonomic and the central nervous systems), and their interactions with drugs (hypnotics and analgesics), can lead to a better understanding of the anesthetic-induced changes and so the global behaviors of the systems. Nevertheless modeling approaches are confronted with some fundamental questions as their identification, the choice of the description level, the measure of relative quality between models, and the evaluation of performances (81). With the help of signal processing techniques and data fusion methods (82-84), such a modeling can bring significant progresses in the monitoring of anesthesia's agents.

Works dedicated to these issues concerned the mono-variable hemodynamics control (blood pressure) (85), the bi-variables hemodynamics control (blood pressure and cardiac output) $(86,87)$ or the control of propofol concentration (88). Most of the modeling techniques are based on compartmental approach $(89,90)$. From the theoretical point of view, these models are well known and their limits are clearly identified. It is their physiological foundation and their multisystem-multivariable articulation that might be questionable. In deed, It is important to note that controversies persist on the underlying mechanisms of the anesthesia (91, 92). In spite of numerous works concerning the effect of opioids on the respiratory depression, it is only recently that a first pharmacokinetic-pharmacodynamic model was proposed (93). Likewise, the capacity of global physiological models (integrating functions 
driving the distribution and the elimination of opioids) to predict their concentrations is far from being guaranteed (94). By changing the level of description from macroscopic to microscopic, a significant gain can be expected as demonstrated in other biomedical areas (95, 96) and which, for example, could explain the reversible changes observed in different modalities of electroencephalography during anesthesia (97). However, only very few research are reported on the effect of anesthetics on the mechanism of the potassium currents (ionic channels) (91).

Models can be used for simulation, i.e. as generators of physiologically based observations and scenarios. In this case they allow, a better understanding of dose-effect relations, identifying the determinants of observed variabilities, and so to individualize and to optimize clinical protocols. A more ambitious application consists of identifying on the basis of measured signals, a physiological model for which parameters or structures are dynamically configurable to allow integrating the patient status. Such a system would directly open the way to an efficient and reliable closed-loop control of both the hypnotic and the analgesic parts of an anesthesia.

\section{Références}

1. La pratique de l'anesthésie en France en 1996. Ann Fr Anesth Reanim 1998;17(11).

2. Rapport sur la sécurité anesthésique: Ecole Nationale de la Santé Publique; 1994.

3. Hatton F, Tiret L, Maujol L, N'Doye P, Vourc'h G, Desmonts J. Enquête épidémiologique sur les accidents d'anesthésie. Premiers résultats. Ann Fr Anesth Reanim 1983;2(5):331-86. 
4. Drader K, Herrick I. Carotid endarterectomy: monitoring and its effect on outcome. Anesthesiol Clin North America 1997;15:613-28.

5. Mahla E. The electroencephalogram in operating room. Seminar in anesthesia 1997;16:3-13.

6. Prior P. The rationale and utility of neurophysiological investigations in clinical monitoring for brain and spinal cord ischaemia during surgery and intensive care. Comput Methods Programs Biomed 1996;51(1-2):13-27.

7. Guerit JM. Neuromonitoring in the operating room: why, when, and how to monitor? Electroencephalogr Clin Neurophysiol 1998;106(1):1-21.

8. Bikford R. Automatic electroencephalographic control of general anesthesia. Electroencephalogr Clin Neurophysiol 1950;2:93-6.

9. Herregods L, Rolly G. The EMG, the EEG zero crossing frequency and mean integrated voltage analysis during sleep and anesthesia. In: Rosen M, Lunn J, editors. Consciousness, Awareness and Pain in General Anesthesia. London: Butterworths; 1987. p. 83-8.

10. Herregods L, Rolly G, Dutre C, Mergaert C, Mortier E. Quantitative evaluation of adequacy of clinical anesthesia ; personal experience with anesthesia and brain activity monitor. In: Bonke B, Fitch W, Millar K, editors. Memory and Awareness in Anesthesia: Swets and Zeitlinger; 1990. p. 365-70.

11. Couture L, Greenwald B, Edmonds H. Detection of responsiveness during anesthesia. In: Bonke B, Fitch W, Millar K, editors. Memory and Awareness in Anesthesia. Amsterdam: Swets and Zeitlinger; 1990. p. 320-9.

12. Vijn PC, Sneyd JR. I.v. anaesthesia and EEG burst suppression in rats: bolus injections and closed-loop infusions. Br J Anaesth 1998;81(3):415-21. 
13. Bikford R. Use of frequency determination in the automatic electroencephalographic control of anesthesia (servoanesthesia). Electroencephalogr Clin Neurophysiol 1951;3:83-6.

14. Findeiss JC, Kien GA, Huse KO, Linde HW. Power spectral density of the electroencephalogram during halothane and cyclopropane anesthesia in man. Anesth Analg 1969;48(6):1018-23.

15. Bart AJ, Homi J, Linde HW. Changes in power spectra of electroencephalograms during anesthesia with fluroxene, methoxyflurane and ethrane. Anesth Analg 1971;50(1):5363.

16. Smith NT, Rampil IJ, Sasse F, Hoff B, Flemming D. EEG during rapidly changing halothane or enflurane. Anesthesiology 1979;51:S4.

17. Levy WJ. Power spectrum correlates of changes in consciousness during anesthetic induction with enflurane. Anesthesiology 1986;64(6):688-93.

18. Rampil IJ, Sasse F, Laster MJ, Smith NT, Hoff B, Flemming D. Spectral edge frequency-anew correlate of anesthetic depth. Anesthesiology 1980;53:S12.

19. Schwilden H, Schuttler J, Stoeckel H. Closed-loop feedback control of methohexital anesthesia by quantitative EEG analysis in humans. Anesthesiology 1987;67(3):341-7.

20. Stoeckel H, Schwilden H. Median EEG frequency. In: Rosen M, Lunn J, editors. Consciousness, Awareness and Pain in General Anesthesia: Butterworths; 1987. p. 53-60.

21. Shah N, Spydell J, Desiderio D, Bedford R. Processed EEG monitoring for preventing awareness during light isoflurane/fentanyl anesthesia. In: Bonke B, Fitch W, Millar K, editors. Memory and Awareness in Anesthesia: Swets and Zeitlinger; 1990. p. 378-81.

22. Withington PS, Morton J, Arnold R, Sebel PS, Moberg R. Assessment of power spectral edge for monitoring depth of anaesthesia using low methohexitone infusion. Int $\mathrm{J}$ Clin Monit Comput 1986;3(2):117-22. 
23. Thomsen CE, Rosenfalck A, Norregaard Christensen K. Assessment of anaesthetic depth by clustering analysis and autoregressive modelling of electroencephalograms. Comput Methods Programs Biomed 1991;34(2-3):125-38.

24. Rampil IJ, Laster MJ. No correlation between quantitative electroencephalographic measurements and movement response to noxious stimuli during isoflurane anesthesia in rats. Anesthesiology 1992;77(5):920-5.

25. Dwyer RC, Rampil IJ, Eger EI, 2nd, Bennett HL. The electroencephalogram does not predict depth of isoflurane anesthesia. Anesthesiology 1994;81(2):403-9.

26. Sebel PS, Bovill JG, Wauquier A, Rog P. Effects of high-dose fentanyl anesthesia on the electroencephalogram. Anesthesiology 1981;55(3):203-11.

27. Bovill JG, Sebel PS, Wauquier A, Rog P. Electroencephalographic effects of sufentanil anaesthesia in man. Br J Anaesth 1982;54(1):45-52.

28. Amaki Y, Horiguchi T, Kobayashi K. EEG analysis of effetiveness of the benzodiazepine-antogonist flyumazenil after diazepam sedation. In: Bonke B, Fitch W, Millar K, editors. Memory and Awareness in Anesthesia. msterdam: Swets and Zeitlinger; 1990. p. 286-7.

29. Traast HS, Kalkman CJ. Electroencephalographic characteristics of emergence from propofol/sufentanil total intravenous anesthesia. Anesth Analg 1995;81(2):366-71.

30. McEwen JA, Anderson GB, Low MD, Jenkins LC. Monitoring the level of anesthesia by automatic analysis of spontaneous EEG activity. IEEE Trans Biomed Eng 1975;22(4):299305.

31. Dutton R, Smith W, Smith NT. Does the EEG predict anesthetic depth better than cardiovascular variables? Anesthesiology 1990;73:A:535. 
32. Veselis RA, Reinsel R, Wronski M. Analytical methods to differentiate similar electroencephalographic spectra: neural network and discriminant analysis. J Clin Monit 1993;9(4):257-67.

33. Ning TK, Bronzino JD. Bispectral analysis of the rat EEG during various vigilance states. IEEE Trans Biomed Eng 1989;36(4):497-9.

34. Rampil IJ. A primer for EEG signal processing in anesthesia. Anesthesiology 1998;89(4):980-1002.

35. Bowles SM, Sebel P, Saini V, Chamoun N. Effects of anesthesia on the EEG Bispectral analysis correlates with movement. In: Sebel P, Bonke B, Winograd E, editors. Memory and Awareness in Anesthesia. Englewood Cliffs, NJ: Prentice Hall; 1993. p. 249-54. 36. Kearse LA, Jr., Manberg P, Chamoun N, deBros F, Zaslavsky A. Bispectral analysis of the electroencephalogram correlates with patient movement to skin incision during propofol/nitrous oxide anesthesia. Anesthesiology 1994;81(6):1365-70.

37. Sebel PS, Bowles SM, Saini V, Chamoun N. EEG bispectrum predicts movement during thiopental/isoflurane anesthesia. J Clin Monit 1995;11(2):83-91.

38. Kearse LA, Jr., Manberg P, DeBros F, Chamoun N, Sinai V. Bispectral analysis of the electroencephalogram during induction of anesthesia may predict hemodynamic responses to laryngoscopy and intubation. Electroencephalogr Clin Neurophysiol 1994;90(3):194-200.

39. Vernon JM, Lang E, Sebel PS, Manberg P. Prediction of movement using bispectral electroencephalographic analysis during propofol/alfentanil or isoflurane/alfentanil anesthesia. Anesth Analg 1995;80(4):780-5.

40. Sebel PS, Lang E, Rampil IJ, White PF, Cork R, Jopling M, et al. A multicenter study of bispectral electroencephalogram analysis for monitoring anesthetic effect. Anesth Analg 1997;84(4):891-9. 
41. Katoh T, Suzuki A, Ikeda K. Electroencephalographic derivatives as a tool for predicting the depth of sedation and anesthesia induced by sevoflurane. Anesthesiology 1998;88(3):642-50.

42. Glass PS, Bloom M, Kearse L, Rosow C, Sebel P, Manberg P. Bispectral analysis measures sedation and memory effects of propofol, midazolam, isoflurane, and alfentanil in healthy volunteers. Anesthesiology 1997;86(4):836-47.

43. Song D, Joshi GP, White PF. Titration of volatile anesthetics using bispectral index facilitates recovery after ambulatory anesthesia. Anesthesiology 1997;87(4):842-8.

44. Barr G, Jakobsson JG, Owall A, Anderson RE. Nitrous oxide does not alter bispectral index: study with nitrous oxide as sole agent and as an adjunct to i.v. anaesthesia. $\mathrm{Br} \mathrm{J}$ Anaesth 1999;82(6):827-30.

45. Muthuswamy J, Roy RJ. The use of fuzzy integrals and bispectral analysis of the electroencephalogram to predict movement under anesthesia. IEEE Trans Biomed Eng 1999;46(3):291-9.

46. Allison T, Goff W, Lyons W, Fisher T. Origin of early auditory evoked potentials in mans : effects of barbiturate anesthesia. Electroencephalogr Clin Neurophysiol 1971;31:451.

47. Thornton C, Heneghan CP, Navaratnarajah M, Bateman PE, Jones JG. Effect of etomidate on the auditory evoked response in man. Br J Anaesth 1985;57(6):554-61.

48. Thornton C, Heneghan CP, Navaratnarajah M, Jones JG. Selective effect of althesin on the auditory evoked response in man. Br J Anaesth 1986;58(4):422-7.

49. Chassard D, Joubaud A, Colson A, Guiraud M, Dubreuil C, Banssillon V. Auditory evoked potentials during propofol anaesthesia in man. Br J Anaesth 1989;62(5):522-6.

50. Schwender D, Rimkus T, Haessler R, Klasing S, Poppel E, Peter K. Effects of increasing doses of alfentanil, fentanyl and morphine on mid- latency auditory evoked potentials. Br J Anaesth 1993;71(5):622-8. 
51. Mark JB, Greenberg LM. Intraoperative awareness and hypertensive crisis during high-dose fentanyl-diazepam-oxygen anesthesia. Anesth Analg 1983;62(7):698-700.

52. Thornton C, Catley DM, Jordan C, Lehane JR, Royston D, Jones JG. Enflurane anaesthesia causes graded changes in the brainstem and early cortical auditory evoked response in man. Br J Anaesth 1983;55(6):479-86.

53. Thornton C, Heneghan CP, James MF, Jones JG. Effects of halothane or enflurane with controlled ventilation on auditory evoked potentials. Br J Anaesth 1984;56(4):315-23.

54. Heneghan CP, Thornton C, Navaratnarajah M, Jones JG. Effect of isoflurane on the auditory evoked response in man. Br J Anaesth 1987;59(3):277-82.

55. Madler C, Keller I, Schwender D, Poppel E. Sensory information processing during general anaesthesia: effect of isoflurane on auditory evoked neuronal oscillations. $\mathrm{Br} \mathrm{J}$ Anaesth 1991;66(1):81-7.

56. Doi M, Gajraj RJ, Mantzaridis H, Kenny GN. Prediction of movement at laryngeal mask airway insertion: comparison of auditory evoked potential index, bispectral index, spectral edge frequency and median frequency. Br J Anaesth 1999;82(2):203-7.

57. Davies FW, Mantzaridis H, Kenny GN, Fisher AC. Middle latency auditory evoked potentials during repeated transitions from consciousness to unconsciousness. Anaesthesia 1996;51(2):107-13.

58. Newton DE, Thornton C, Konieczko KM, Jordan C, Webster NR, Luff NP, et al. Auditory evoked response and awareness: a study in volunteers at sub- MAC concentrations of isoflurane. Br J Anaesth 1992;69(2):122-9.

59. Mantzaridis H, Kenny GN. Auditory evoked potential index: a quantitative measure of changes in auditory evoked potentials during general anaesthesia. Anaesthesia 1997;52(11):1030-6. 
60. Gajraj RJ, Doi M, Mantzaridis H, Kenny GN. Analysis of the EEG bispectrum, auditory evoked potentials and the EEG power spectrum during repeated transitions from consciousness to unconsciousness. Br J Anaesth 1998;80(1):46-52.

61. Gajraj RJ, Doi M, Mantzaridis H, Kenny GN. Comparison of bispectral EEG analysis and auditory evoked potentials for monitoring depth of anaesthesia during propofol anaesthesia. Br J Anaesth 1999;82(5):672-8.

62. Huang JW, Lu YY, Nayak A, Roy RJ. Depth of anesthesia estimation and control. IEEE Trans Biomed Eng 1999;46(1):71-81.

63. Akselrod S, Gordon D, Ubel FA, Shannon DC, Berger AC, Cohen RJ. Power spectrum analysis of heart rate fluctuation: a quantitative probe of beat-to-beat cardiovascular control. Science 1981;213(4504):220-2.

64. Malliani A, Pagani M, Lombardi F, Cerutti S. Cardiovascular neural regulation explored in the frequency domain. Circulation 1991;84(2):482-92.

65. Ireland N, Meagher J, Sleigh JW, Henderson JD. Heart rate variability in patients recovering from general anaesthesia. Br J Anaesth 1996;76(5):657-62.

66. Galletly DC, Westenberg AM, Robinson BJ, Corfiatis T. Effect of halothane, isoflurane and fentanyl on spectral components of heart rate variability. $\mathrm{Br} \mathrm{J}$ Anaesth 1994;72(2):177-80.

67. Kato M, Komatsu T, Kimura T, Sugiyama F, Nakashima K, Shimada Y. Spectral analysis of heart rate variability during isoflurane anesthesia. Anesthesiology 1992;77(4):66974.

68. Kawamoto M, Kaneko K, Hardian, Yuge O. Heart rate variability during artificial ventilation and apnea in brain- damaged rabbits. Am J Physiol 1996;271(2 Pt 2):H410-6. 
69. Mazerolles M, Senard JM, Verwaerde P, Tran MA, Montastruc JL, Virenque C, et al. Effects of pentobarbital and etomidate on plasma catecholamine levels and spectral analysis of blood pressure and heart rate in dogs. Fundam Clin Pharmacol 1996;10(3):298-303.

70. Schubert A, Palazzolo JA, Brum JM, Ribeiro MP, Tan M. Heart rate, heart rate variability, and blood pressure during perioperative stressor events in abdominal surgery. $\mathrm{J}$ Clin Anesth 1997;9(1):52-60.

71. Donchin Y, Feld JM, Porges SW. Respiratory sinus arrhythmia during recovery from isoflurane-nitrous oxide anesthesia. Anesth Analg 1985;64(8):811-5.

72. Deutschman CS, Harris AP, Fleisher LA. Changes in heart rate variability under propofol anesthesia: a possible explanation for propofol-induced bradycardia. Anesth Analg 1994;79(2):373-7.

73. Yli-Hankala A, Jantti V. EEG burst-suppression pattern correlates with the instantaneous heart rate under isoflurane anaesthesia. Acta Anaesthesiol Scand 1990;34(8):665-8.

74. Yli-Hankala A, Heikkila H, Varri A, Jantti V. Correlation between EEG and heart rate variation in deep enflurane anaesthesia. Acta Anaesthesiol Scand 1990;34(2):138-43.

75. Yli-Hankala A, Loula P, Annila P, Lindgren L, Jantti V. Atropine abolishes electroencephalogram-associated heart rate changes without an effect on respiratory sinus arrhythmia during anaesthesia in humans. Acta Physiol Scand 1993;149(4):435-40.

76. Sleigh JW, Donovan J. Comparison of bispectral index, 95\% spectral edge frequency and approximate entropy of the EEG, with changes in heart rate variability during induction of general anaesthesia. Br J Anaesth 1999;82(5):666-71.

77. Bennett HL. F.A.C.E : a sensitive and specific monitor for the adequacy ('depth') of anesthesia. In: Sebel P, Bonke B, Winograd E, editors. Memory and Awareness in Anesthesia. Englewood Cliffs, NJ: Prentice Hall; 1993. p. 249-254. 
78. Struys M, Versichelen L, Mortier E, Ryckaert D, De Mey JC, De Deyne C, et al. Comparison of spontaneous frontal EMG, EEG power spectrum and bispectral index to monitor propofol drug effect and emergence. Acta Anaesthesiol Scand 1998;42(6):628-36.

79. Evans JM, Bithell JF, Vlachonikolis IG. Relationship between lower oesophageal contractility, clinical signs and halothane concentration during general anaesthesia and surgery in man. Br J Anaesth 1987;59(11):1346-55.

80. Cox P, White D. Do esophageal concentrations measure 'depth' of anesthesia? Br J Anaesth 1986;58:131P-132P.

81. Coatrieux J. Issues on signal processing and physiological modeling. Part II: Depth model-driven analysis. Crit Rev Biomed Eng 2002.

82. Waltz E, Buede D. Data fusion and decision support for command and control. IEEE Trans Syst Man Cybern 1986;16:865-79.

83. Luo R, Kay M. Multisensor integration and data fusion in intelligent systems. IEEE Trans Syst Man Cybern 1989;19:901-31.

84. Dasarathy B. Decision fusion strategies in multisensor environments. IEEE Trans Syst Man Cybern 1991;21:1140-54.

85. Isaka S, Sebald AV. Control strategies for arterial blood pressure regulation. IEEE Trans Biomed Eng 1993;40(4):353-63.

86. Yu C, Roy RJ, Kaufman H, Bequette BW. Multiple-model adaptive predictive control of mean arterial pressure and cardiac output. IEEE Trans Biomed Eng 1992;39(8):765-78.

87. Voss GI, Katona PG, Chizeck HJ. Adaptive multivariable drug delivery: control of arterial pressure and cardiac output in anesthetized dogs. IEEE Trans Biomed Eng 1987;34(8):617-23.

88. Kenny GN, White M. A portable computerised infusion system for propofol. Anaesthesia 1990;45(8):692-3. 
89. Rao RR, Bequette BW, Roy RJ. Simultaneous regulation of hemodynamic and anesthetic states: a simulation study. Ann Biomed Eng 2000;28(1):71-84.

90. Gentilini A, Frei CW, Glattfedler AH, Morari M, Sieber TJ, Wymann R, et al. Multitasked closed-loop control in anesthesia. IEEE Eng Med Biol Mag 2001;20(1):39-53.

91. Friederich P, Urban BW. Interaction of intravenous anesthetics with human neuronal potassium currents in relation to clinical concentrations. Anesthesiology 1999;91(6):1853-60.

92. Cariani P. Anesthesia, neural information processing, and conscious awareness. Conscious Cogn 2000;9(3):387-95.

93. Bouillon T, Schmidt C, Garstka G, Heimbach D, Stafforst D, Schwilden H, et al. Pharmacokinetic-pharmacodynamic modeling of the respiratory depressant effect of alfentanil. Anesthesiology 1999;91(1):144-55.

94. Bjorkman S, Wada DR, Stanski DR. Application of physiologic models to predict the influence of changes in body composition and blood flows on the pharmacokinetics of fentanyl and alfentanil in patients. Anesthesiology 1998;88(3):657-67.

95. Bardou AL, Auger PM, Birkui PJ, Chasse JL. Modeling of cardiac electrophysiological mechanisms: from action potential genesis to its propagation in myocardium. Crit Rev Biomed Eng 1996;24(2-3):141-221.

96. Wendling F, Bellanger JJ, Bartolomei F, Chauvel P. Relevance of nonlinear lumpedparameter models in the analysis of depth- EEG epileptic signals. Biol Cybern 2000;83(4):367-78.

97. Karasawa H, Sakaida K, Noguchi S, Hatayama K, Naito H, Hirota N, et al. Intracranial electroencephalographic changes in deep anesthesia. Clin Neurophysiol 2001;112(1):25-30. 